DOI: 10.1515/ausp-2016-0025

\title{
Organized Chaos: Cohesive Devices in Benjy's Sections of William Faulkner's The Sound and the Fury
}

\author{
Aliz FARKAS \\ Sapientia Hungarian University of Transylvania (Miercurea Ciuc, Romania) \\ Department of Humanities \\ farkasaliz@yahoo.com
}

\begin{abstract}
As the history of criticism on The Sound and the Fury proves it, Benjy's section is probably the most controversial part of the novel. Some literary critics and writers celebrated it as an excellent piece of literary art, the peak of writerly performance, while others felt confused and irritated over the trials it posed to the reader.

Although critical voices that reproach the writer for the incoherence of Benjy's narrative may be justified at first sight, a closer inspection reveals that it is much less incoherent than it appears. In my paper, I will argue that there are several ways in which the author helps the reader to construct a more or less coherent story line out of the fragmented events that happened in the course of about thirty years. Secondly, I want to demonstrate that functional-semantic approaches to text analysis, such as Systemic Functional Grammar or Text Linguistics, can be effectively employed in analysing and interpreting literary texts. Finally, I try to find a psychological explanation of how Benjy's incoherence is made readable by the interworking between the coherence-seeking dispositions of the reader and the ingenious cohesive devices used by the writer.
\end{abstract}

Keywords: William Faulkner, Benjy, text linguistics, cohesive devices

\section{Introduction}

Much of the incomprehension and puzzlement experienced by both early and later readers of The Sound and the Fury is attributed to the fragmentariness of Benjy's section. Benjy's part is written in such a way that it only partially satisfies the curiosity of the reader who - in line with the normal endeavour of all readers - wants to decipher the story behind the discourse, and expects a clearcut plotline. A major difficulty the reader has to face is that the chronology of the 
story is scrambled, memory flashbacks from different past events are interspersed with events happening in the narrative present. Not only that, but it is often unclear whether the events being related at a given point in the narrative are taking place in the narrative present or in the past (the fact that past tense is used throughout the narrative present adds to the confusion). Another challenge posed by Benjy's narrative is the fact that the past events related in the memory flashbacks do not belong to a single sequence of events. There are more than a dozen shorter or longer episodes from different points of the past the fragments of which are mixed throughout the narrative. No wonder then that so much ink has been spilled over "straightening" Benjy's story by establishing the chronological order of the events (Steward \& Backus 1958, Volpe 1964, Ross \& Polk 1996).

Faulkner himself attempted in 1946 to "straighten" the story by writing an appendix to The Portable Faulkner edition of his selected works and insisting that it should serve as an introduction to later editions of the novel. But even at the time of writing he had doubts whether it was a good idea to start the novel with the part most difficult to follow. It was only after a series of experiments of moving it to and fro within the novel that he finally decided to leave it where it initially had been placed: at the beginning. Whether this reflects an authorial intention or not, Benjy's part functions as a trial for testing the commitment of the reader: those who persist in moving on despite all the obstacles they have to face qualify themselves as "resilient readers". Benjy's section requires a resilient reader tolerating ambiguity, capable of figuring out the author's novelistic conventions and dropping them as soon as they prove to be misleading, and eager to revise his interpretation whenever new elements appearing in the narrative require it, no matter how frequently this happens.

If I wanted to find a visual image comparable to Benjy's part, I would compare it to a finely sewn, varicoloured patchwork. ${ }^{1}$ An aesthetically appealing patchwork measures up to two different expectations at the same time: variegation and cohesion. Cohesion is assured by the reiteration of patches of the same colour as well as by the stitches that keep the individual patches together. In a similar manner, the cohesion of Benjy's narrative is assured by the reiteration of certain topics, motifs, and symbols, and by the way the different textual fragments are linked to one another. In this paper, I will present the results of my analysis applied to Benjy's section the goal of which was to identify the cohesive devices that hold the textual fragments together and the ways in which the author helps the reader to construct a more or less coherent storyline.

1 This might not be a daring idea in the light of Faulkner's confession according to which his intention was to have the first part of the book printed in many different colours in order to help the reader keep track of the events happening at different points in time (see: Gwynn \& Blotner 1959: 94). His dream was fulfilled eighty years later, when The Folio Society released a colourcoded special edition of the novel in 2012. 


\section{The concepts of coherence and cohesion; method of analysis}

There has been considerable discussion in the specialist literature about the conditions a set of sentences has to meet so that it can be considered to form a coherent text. A highly inclusive definition of a cohesive text is offered by Brown and Yule (1983), who relegate responsibility for textual coherence to the reader by saying that "texts are what hearers and readers treat as texts" (199). Other theorists, like Halliday and Hasan (1976), claim that cohesion markers, such as reference, substitution, ellipsis, and lexical relationships, are indispensable ingredients of a coherent text even though they finally admit that "it is the underlying semantic relation [...] that actually has the cohesive power" (229).

For the sake of clarity, I will adopt the definitions of coherence and cohesion as they are given in The Routledge dictionary of language and linguistics (1996). According to this, coherence "specifically signifies the semantic meaning and the cohesion of the basic interconnection of the meanings of the text, its content/ semantic and cognitive structure. Semantic coherence can be represented as a sequence of propositions that form a constellation of abstract concepts and connected relations" (198).

Cohesion, on the other hand, "refers to the various linguistic means (grammatical, lexical, phonological) by which sentences 'stick together' and are linked into larger units of paragraphs, or stanzas, or chapters. Cohesion is produced by (a) the repetition of elements of the text, e.g. recurrence, textphoric, paraphrase, parallelism; (b) the compacting of text through the use of devices such as ellipsis; (c) the use of morphological and syntactic devices to express different kinds of relationships such as connection, tense, aspect, deixis, or theme-rheme relationships" (199).

I will use the patchwork metaphor introduced above to illustrate what exactly I have examined. First, I looked at the ways in which the present and the past fragments of the narrative are linked to one another, that is, the stitches which hold the patches together. More specifically, I looked for instances of lexical and syntactic repetition, development of semantic fields related to important topics (e.g. death), and co-referential use of pronouns (anaphora, cataphora). However, instead of making an inventory of the cohesive devices used in Benjy's section, I applied a more functional approach by focusing on the effects the use of such devices might have upon the reader. Apart from the grammatical and lexical cohesive devices specified above, I also considered visual clues such as the use of different typefaces to signal transitions between time levels. To this end, I read the text unit by unit and described the grammatical, lexical, and visual devices that are used for signalling time shifts and assuring cohesion. 
Then, I examined the devices that link the fragments belonging to the same time level together, that is, the way in which the same coloured patches cohere. In order to do this, I created a separate document for each time level where I collected all the fragments belonging to that particular level, and analysed the language used in the different levels. My intention was to identify those themes and lexical elements (e.g. proper names) that link the fragments of the same time level together.

The very first step in the process of analysis consisted of establishing the number of fragments and that of the time levels. This proved to be much more complicated than it had seemed at first sight. After several attempts, I realized that what counted as a separate textual fragment or a different time level was not so obvious at all: it was often a matter of interpretation. So, instead of carrying out the whole work myself, I decided to review the literature available on this topic, and to rely on the findings. I found a great diversity across studies with respect to the number of fragments and time levels. Olga Vickery (1954), for instance, interpreted the text as consisting of "four extended episodes" completed with shorter "recollections", Cleanth Brooks (1952) divided the section into eleven various "experiences", Edmund L. Volpe (1964) identified sixteen levels, while Stephen M. Ross and Noel Polk (1996) found fourteen different time levels. After a thorough analysis of Benjy's section, George R. Stewart and Joseph M. Backus (1958) divided it into 106 "units", and arranged the fragments into thirteen different "time levels". They based their analysis almost entirely on the text itself, but on some occasions they also looked for corroboration in other texts such as the other three sections of the novel, Faulkner's later short stories and novels, and the appendix attached to the book in 1946. Since I found their analysis and their argumentation for it convincing and because their analysis had been based almost exclusively on the text involving as little speculation as possible, I decided to use their study as the starting point of my own analysis. Stewart and Backus summarized their findings in two tables: the first one comprises the numbers of the 106 fragments accompanied by the first line of each fragment as identified by the authors (443). The second table contains the 13 levels arranged in chronological order as reconstructed by the authors of the study, together with the numbers of the fragments belonging to each time level (444). For more recent analyses of the cohesive devices in the novel, see also Toolan (1998) and Tennent (2015).

I used the 1956 Random House edition of The Sound and the Fury for the present analysis, which is a photographical reproduction of the novel's 1929 edition. The Arabic numbers without brackets refer to the number of the units as identified by Stewart and Backus, while the numbers in brackets after the quotations indicate the page on which the fragment in question can be found in this edition. 


\section{Findings}

Out of the thirteen longer or shorter plot threads, the event sequence of the narrative present (Luster and Benjy's wandering around the Compson estate on April seventh, 1928) emerges as the backbone of the narrative to which all the memory clusters are metonymically attached. Metonymy is the organizing principle that integrates memories into the current flow of events. The metonymy involved in triggering time shifts can be spatial (a certain spot on the Compson estate evokes a past event that took place at the same location), sensual (a current sensual perception recalls a similar experience from the past), or referential (a certain person or name brings up childhood memories related to the same person or to another person with the same name). The fragments belonging to the present level are evenly distributed throughout the section, usually every second or third fragment shifting back to the present. However, there are several instances in the narrative where the intruding memory fragments are more numerous, the distance between two consecutive present units becoming longer. The narrative strategy seems to be that whenever life-changing events are involved, they are foregrounded to such an extent that the present level is unable to intrude in spite of its immediacy and prevalence in most parts of Benjy's section. Apart from "The Present" time level consisting of 32 textual fragments, the time levels involving the largest number of fragments are the ones that carry Benjy's earliest childhood memories: "Damuddy's Death" and "The Name-Changing". The "Damuddy's Death" level starts quite early on in the narrative, and - just as "The Present" level - it becomes a consistently foregrounded time level throughout the narrative. We can say that, in a way, these two levels demarcate the distal ends of the narrated time continuum, setting a time-frame for Benjy's section. The cohesion of the less consistent time levels (those involving less fragments) is facilitated by their concentration to a given part of the narrative, that is - apart from several exceptional dislocations - their fragments being placed relatively close to one another.

Typeface change (from Roman to italics and vice versa) is used to signal shifts between time levels. However, the convention of typeface change is constantly modified: the initial association of the narrative present with the Roman types and the memory fragments with the italics is soon dropped, time shifts being signalled by the use of different typefaces irrespective whether the shift takes place between present and past or two past time levels. On some occasions, only the first sentence of a fragment is written in italics, while at other times typeface change is dropped altogether, and time shift is not signalled in any way. The inconsistencies in the use of typeface change can become misleading for readers who rely on such clues too heavily, as if Faulkner wanted to show that the mechanical following of conventions is not rewarding, the reader has to stay alert all the time. 
Sometimes typeface change has other functions than signalling time shift. At one point in the narrative, typeface change occurs in fragment-internal position, having the pragmatic function of differentiating between words genuinely addressed to Benjy eliciting his collaboration, such as Versh's commands, and utterances that are addressed to him but not interpreted by him as such: ${ }^{2}$

We went back. "You must think." Mother said. Hold still now Versh said. He put my overshoes on. "Someday I'll be gone, and you'll have to think for him." Now stomp Versh said. "Come here and kiss Mother, Benjamin." (8)

On several occasions, the time shift - signalled by the change of typeface - takes place in the middle of a sentence. For example, time shift from April seventh, 1928 ("The Present" level) to early fall, 1898 ("Damuddy's Death") is signalled by sentence-internal typeface change:

"Now, git in that water and play and see can you stop that slobbering and moaning."

I hushed and got in the water and Roskus came and said to come to supper and Caddy said, It's not supper time yet. I'm not going. (19)

The effect of this technique is that the two fragments - and the two water scenes at the branch related to different time levels - are more strongly intertwined, and the temporal gap is smoothly bridged.

A similar technique is used on page 75, where time shift from November, 1900 ("The Name-Changing”) to early fall, 1898 ("Damuddy's Death") is signalled by line-internal typeface change:

I can carry him, Caddy said. "Let me carry him up, Dilsey.” (75)

This ingenious method is just one of the cohesive devices employed in linking consecutive textual fragments.

The repetition of a proper name in a subsequent fragment is another way of making the text cohere. Sometimes the name refers to the same person but at different times and sometimes it refers to two different persons (e.g. the name Quentin can refer to Benjy's brother or to his niece). An example for the former case is the following passage, in which we can see Jason as a child in 1900 and as an adult in 1928:

2 On a different interpretation of this fragment-internal typeface change, see Ross and Polk 1996: 13. 
"Hush.” Father said. "Jason.” he said.

"I'll make you some more tomorrow." Caddy said. "We'll make a lot of them. Here, you can look at the cushion, too."

Jason came in. (80)

The passage below exemplifies the second case, where the name "Quentin" first refers to Benjy's niece in 1928, and then to his brother in 1900:

Dilsey went away. "Quentin." She said in the hall. "Quentin. Supper is ready."

We could hear the roof. Quentin smelled like rain, too. (81)

This technique shapes a narrative that makes possible for the reader to perceive the child self and the adult self of the character almost simultaneously, or puzzle him with the ambiguities in the representation of the character named Quentin.

The common indicator of textual cohesion, anaphora, is also employed, but its function surpasses that of assuring local cohesion. Sometimes the antecedent (e.g. "Versh's house") and the subsequent anaphoric pronoun ("it") are separated by a time shift, and thus while they have the same referent (Versh's house), they point to it from two different time perspectives:

I liked to smell Versh's house. There was a fire in it and T.P. squatting in his shirt tail in front of it, chunking it into a blaze. (33)

The object pronoun is correctly interpreted as an anaphoric pronoun referring to the noun "house" - they have the same referent. However, there is a temporal distance of several years between the two scenes - a gap smoothly bridged by a simple cohesive device. In this way, the anaphora has a double function: on the one hand, it assures local cohesion (the two fragments read as a coherent text), while, on the other, it bridges the temporal gap between two time levels.

The same coherence effect is attained by the use of active verbs that logically follow one another. For example, Benjy gets snagged on a nail at the end of a fragment in the present time level, and Caddy frees him at the beginning of the subsequent fragment in the past:

"Wait a minute." Luster said. "You snagged on that nail again. Cant you never crawl through here without snagging on that nail."

Caddy uncaught me and we crawled through. (3) 
Or they start up the hill at the end of one fragment in a certain past time level (in 1910), and they reach the top at the beginning of the following fragment in another past time level (in 1898):

I went on with them, up the bright hill.

At the top of the hill Versh put me down. (26)

The act of starting towards a point in space (the hill) and arriving there gives a sense of progress that helps the reader to bridge the time gap between the two events.

Since the fragments belonging to each of the thirteen time levels are separated from one another by intruding fragments from other time levels, the cohesive devices linking them are different from the ones discussed above.

Repetition or reformulation of the last phrase or sentence from an earlier fragment at the beginning of the subsequent fragment belonging to the same time level operates in two ways. On the one hand, it helps the reader to pick up the narrative string exactly where it has been dropped several pages before and, on the other hand, it gives a sense of duration to the act described in the repeated sentence. For instance, if we hear Luster scold Benjy at the end of one fragment, and we hear him do the same thing at the beginning of another, we have the impression that the scolding was continuously going on, even while we were reading about other events.

The plots of the thirteen time levels differing from one another, the semantic field constructed around certain themes also helps the reader to associate the fragments with the appropriate time levels. The fragments belonging to "Damuddy's Death," for instance, develop the semantic field of "death" (built up by the words "funeral", "dead", "moan”, "buzzard”, "undress") and the rivalling semantic field of a happy gathering (including words such as "company", "party", "music”, "sing”). In the same vein, the fragments associated with the "Caddy's Wedding" level contain words related to the semantic field of drinking, such as "sassprilluh", "cellar", "drink", and "bottle", as well as the expressions referring to the sounds the two characters make like "holler" or the onomatopoeic word "whooey".

Although all thirteen plot threads entertain the same limited number of characters consisting of the Compsons and the black servants, the distribution of the proper names differs depending on the time level. While "Luster" is the most frequently occurring name in "The Present" level, whereas "Caddy" is hardly ever mentioned, she becomes the most prominent figure in the memory levels, accompanied by Benjy’s earlier attendants "Versh" and “T. P.", respectively. In this way, nouns also function as cohesive devices. The significance of names and the act of naming receives special attention in "The Name-Changing" time level, where the narrator's different names ("Benjy”, "Benjamin”, and "Maury”) 
are unusually frequently mentioned. The repetition of the narrator's three names so many times emphasizes the main theme of the time level, namely the namechanging event, and the confusion of identity entailed by it.

The recurring phrase "Caddy smelled like trees" (pages 50, 51, 54, 58) and its variants "Caddy smelled like leaves" (5), "Caddy smelled like trees and like when she says we were asleep" (5), "Caddy smelled like trees in the rain" (22), "She smelled like trees" $(51,88)$ constitute a hyperlink operating across time levels. It recurs ten times throughout the narrative either in fragment-internal position or as a free-floating phrase intruding between two consecutive fragments. It singles out Caddy as the main figure upon whom the cohesion of the whole section hinges.

\section{Final notes}

I am well aware that just like any other analysis the one presented in this paper was also carried out in artificially created conditions which involved dissecting the body of the text, submitting the fragments to combinatorial operations, slowmotion reading and repeated reading - proceedings that are very different from those employed in real-time reading. The question therefore arises as to how many of these cohesive devices are consciously noticed by the real-time reader at all. After all the work I invested in merely identifying them, my intuitive answer would be: not many. Most of them are probably unconsciously registered, some go entirely unnoticed. How, then, is the narrative perceived coherent enough for the reader to keep on reading? A tentative explanation to this phenomenon comes from the psychologist Daniel Kahneman (2012). He posits the existence of two kinds of coherence: a logical one based on serial operations of reasoning and a less rigorous one called associative/emotional cohesion, achieved through a network of associations activated by a limited number of clues. The two types of cohesion are in fact two different products of the human mind achieved through very different cognitive procedures: logical coherence requires a careful processing of a significant amount of evidence, while associative/emotional coherence is instantaneously created by the network of associations easily put into motion by a few pieces of evidence. Kahneman differentiates between two cognitive systems within the human mind. System 1 is responsible for all fast thinking, intuition, gut feeling, and self-confidence that enable people to assess situations and take quick decisions. It is, in fact, an amazingly efficient storytelling machine capable of creating coherent stories despite scarce evidence through associative memory and emotional reactions. People, then, are prone to take decisions on the basis of the coherence of the story their mind creates, and not on the evidence themselves. System 2, on the other hand, involves slow thinking, focusing, analysing, and it takes time. It functions as a safety system 
in case the coherence of the story is disturbed by conflicting evidence. Since System 1 is in charge most of the time, we can reasonably speculate that it is employed in reading as well, facilitating the reading process by its coherenceseeking, story-telling operations. Thus, the chaos in Benjy's narrative induced by the fragmentation of chronology is appeased and organized by the joint effort of the author and the reader: Faulkner's ingenious cohesive devices, on the one hand, and the reader's pursuit of coherence on the other.

\section{References}

Brooks, Cleanth. 1952. Primitivism in The Sound and the Fury. English Institute Essays 1952. ed. Alan Seymour Downer. 1954: 5-28. New York: Columbia University Press.

Brown, Gillian-Yule, George. 1983. Discourse analysis. Cambridge University Press.

Bussmann, Hadumod. 1996. Routledge dictionary of language and linguistics. London: Routledge.

Faulkner, William. 1956. The Sound and the Fury. New York: Random House.

Gwynn, Frederick L.-Blotner, Joseph L. 1959. Faulkner in the university. Charlottesville, Virginia: The University of Virginia Press.

Halliday, M. A. K.-Hasan, R. 1976. Cohesion in English. London: Longman.

Kahneman, Daniel. 2012. Thinking, fast and slow. Penguin Books.

Ross, Stephen M.-Polk, Noel. 1996. Reading Faulkner: The Sound and the Fury. Jackson: University Press of Mississippi.

Stewart, George R.-Backus, Joseph M. 1958. "Each in its ordered place”: structure and narrative in "Benjy's section" of The Sound and the Fury. American Literature 29(4): 440-456. http://www.jstor.org/stable/2922372.

Tennent, Wayne. 2015. Understanding reading comprehension: processes and practices. London: Sage.

Toolan, Michael. 1998. Language and literature. An introduction to stylistics. London: Routledge.

Vickery, Olga W. 1954. The Sound and the Fury: a study in perspective. PMLA, LXIX: 1017-1037. http://www.jstor.org/stable/459766.

Volpe, Edmund. L. 1964. A reader's guide to William Faulkner. New York: The Noonday Press. 